\title{
Insights Into the Gelation of Biphenyl Coupled Pyridyl Bisamides
}

\author{
Santanu Panja ${ }^{a, b}$ and Kumaresh Ghosh ${ }^{\star, b}$ \\ ${ }^{a}$ School of Chemistry, University of Glasgow, Glasgow, UK, G12 8QQ \\ ${ }^{b}$ Department of Chemistry, Faculty of Science, University of Kalyani, Kalyani-741235, India
}

Email: ghosh_k2003@yahoo.co.in or kumareshchem18@klyuniv.ac.in (K.G.)

\begin{abstract}
Biphenyl coupled isomeric pyridyl bisamides $\mathbf{1 - 4}$ have been synthesized and their gelation propensities have been thoroughly investigated. In spite of having a pyridine center, capable of forming water linking network and hydrogen bonding amide functionality, all the compounds behave as non-gelator in organic and semi aqueous solvents. However, in presence of $\mathrm{Ag}^{+}$ions, only compound $\mathbf{1}$ forms gel and validates its visual sensing over other metal ions. The nongelation behaviour of other derivatives 2, 3 and also meta derivative 4 highlights the effect of positional role of the pyridine ring nitrogen with respect to the biphenyl ring as well as endorse the isomeric substitution in biphenyl ring, respectively. Spectroscopic studies confirm that the metal coordination as well as the hydrogen bonding involving the amide $\mathrm{NHs}$ of $\mathbf{1}$ plays a pivotal role in establishing the gel network in solution. Not only through gelation, compound 1 also selectively recognizes $\mathrm{Ag}^{+}$ions fluorimetrically in a turn-on mode in solution state and correlates the gel phase observations.
\end{abstract}

Keywords supramolecular gels, biphenyl-linked bispyridine amide, stimuli responsiveness, $\mathrm{Ag}^{+}$sensing, fluorometric detection

\section{Introduction}

Supramolecular gels are incredibly important in many areas from medicine to material science. ${ }^{[1-17]}$ These gels are formed when small monomeric units combine to form a larger structure under the influence of various noncovalent forces like hydrogen bonding, $\pi$-stacking, electrostatic, hydrophobic interactions, etc. In general, to bring about self-assembly, usually a trigger like $\mathrm{pH}$, temperature, irradiation, ions, redox, and so on, is applied to the suspension or solution of the gelator. ${ }^{[6-8,12,13,15,18-30]}$ As a result, the solubility of the molecules in solution decreases and self-aggregation occurs. Of various stimuli, metal ion coordination draws attention for visual detection through the conversion a sol state into a metal-organic gel state. ${ }^{[19,21,31-36]}$ Apart from visual detection, the metallogels are widely applicable in catalysis, optoelectronics and medicines. ${ }^{[1,7,13,16,21,31,33,37-46]}$ Metallogels are synthesized based on strong metal-ligand interactions. ${ }^{[21,31,33,35,42,47-57]}$ Metal coordination allows two or more molecules to come closer and simultaneously influences other non-covalent interactions to encourage the growth of assembly in a directional way. However, if the metal-ligand interactions are strong enough, it could lead to precipitation or crystallization..$^{[2,33,35,47-49,52,54]}$ Therefore, a delicate balance between different intermolecular interactions is required to get a metallogel. To explore this, the study on correlation between the gelling behaviour and structural parameters of gelators is being increasingly important by designing new functional architectures. ${ }^{[14,21,38,39,41,42,48,52,58,59]}$

The literature survey reveals that pyridine-containing compounds are promising materials for constructing metallogels. ${ }^{[21,38,39,48-50,59-91]}$ In such compounds, the pyridine moieties are coupled to different spacers through various functional groups like amide, urea, imidazole, imine, etc. Despite information available, it is still unclear why some molecules form gel and some are not. Moreover, in many cases, the bulk phase interactions are found to be dramatically different from that of the microscopic level (in $10^{-5} \mathrm{M}$ )..$^{[39,92,93]}$ Thus, there is enough scope to deal with new molecular systems that are simple and can be easily synthesized for task-specific applications.

In this work, we intend to investigate the structure-property relationship of some isomeric pyridyl bisamides. For this purpose, we synthesized compounds $\mathbf{1}-\mathbf{4}$ by placing different pyridyl motifs around a common biphenyl spacer through amide bond (Figure 1). All the compounds possess pyridine nitrogen and amide functionality for intermolecular hydrogen bonding interaction. They are expected to exhibit different conformations and hydrogen bonding attributes in solution due to the change in position of the pyridine ring nitrogens (1, 2 and $\mathbf{3})$ as well as change in spacer (1 and $\mathbf{4})$. In reality, the compounds behaved differently in self-aggregation. Of the bisamides $\mathbf{1 - 4}$, only compound $\mathbf{1}$ is established as a potential gelator that forms gel in presence of $\mathrm{Ag}^{+}$ions and validates its visual sensing.

Notably, the nongelation behaviour of the derivatives 2 and 3 highlights the positional role of pyridine ring nitrogen with respect to the biphenyl ring during self-aggregation in the presence of $\mathrm{Ag}^{+}$ions. In relation to this, different behaviours of the ortho and meta derivatives 1 and 4, respectively, towards gelation in presence of $\mathrm{Ag}^{+}$ions endorse that the gelation abilities of these molecules significantly depend on the orientation of hydrogen bonding moieties around the spacers used.

Compound 1 further selectively interacts with $\mathrm{Ag}^{+}$ions (as verified by fluorescence and UV-vis) in solution and shows a correlation with the gel phase behavior. Fluorometric sensing of metal ions draws considerable attention due to their environmental and physiological relevance. ${ }^{\text {[94-102] }}$ Of various metal ions, $\mathrm{Ag}^{+}$ion is of great importance as it is associated with bioaccumulation and toxicity. ${ }^{[55,102,103]}$ Additionally, it has considerable applications in photography and imaging industry, organic synthesis, electronics, and so on. ${ }^{[95,103]}$ Thus, selective recognition of $\mathrm{Ag}^{+}$ions is of upmost interest. 


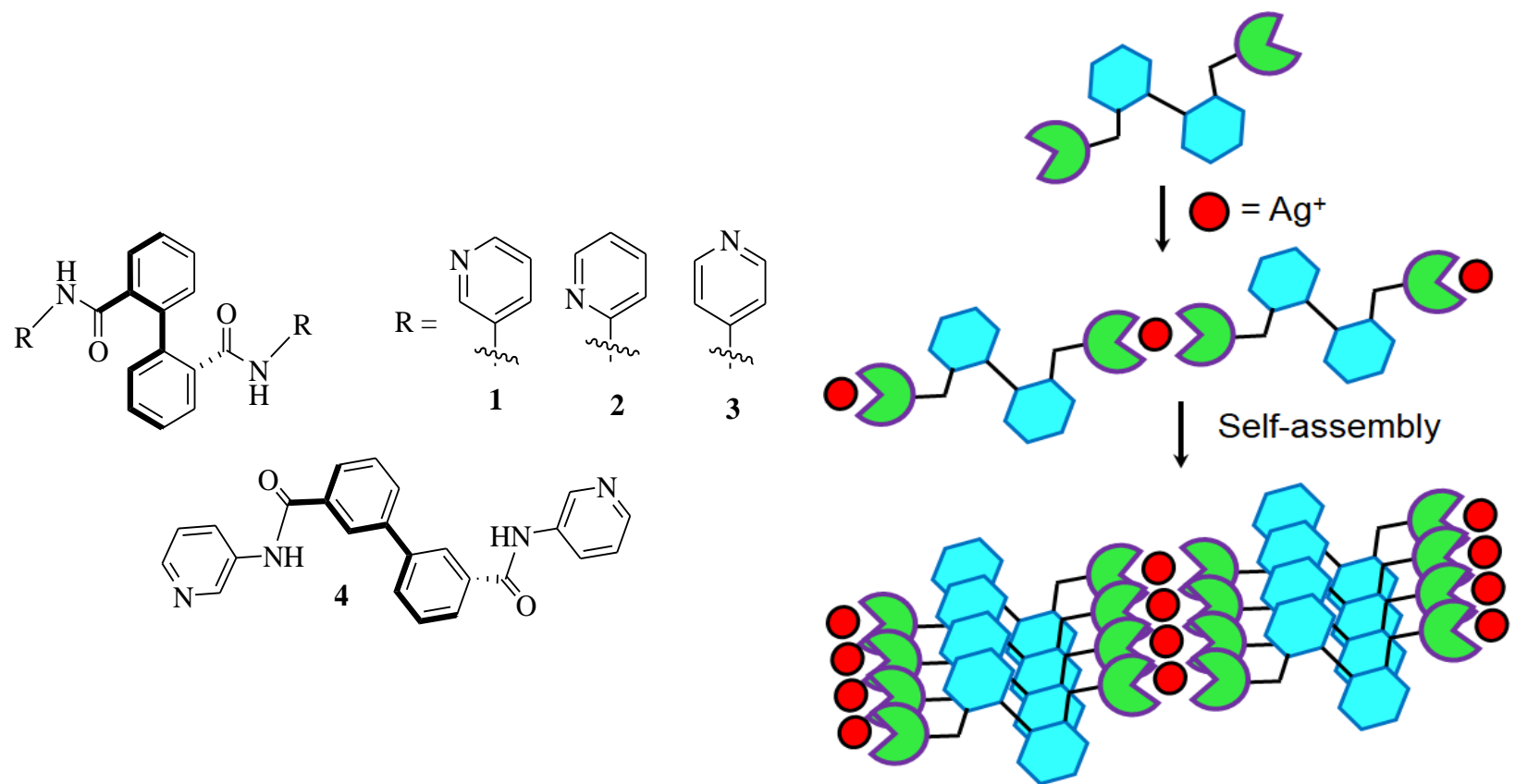

Figure 1 (Left) Structures of compounds 1-4. (Right) Schematic representation of the mode of aggregation of 1 in presence of $\mathrm{Ag}^{+}$ in solution.

\section{Experimental}

\section{Materials and methods}

Reagents and solvents were purified using standard techniques. All solvents used in the synthesis were purified, dried and distilled following standard procedure. Solvents for spectroscopic measurements were of spectroscopic or HPLC grade. Solvents used in NMR experiments were obtained from Aldrich. Thin layer chromatography was performed on Merck precoated silica gel $60-\mathrm{F}_{254}$ plates. ${ }^{1} \mathrm{H}$ NMR and ${ }^{13} \mathrm{C}$ NMR spectra were recorded using Bruker $400 \mathrm{MHz}$ instrument using TMS as internal standard. High resolution mass data were acquired by the electron spray ionization (ESI) technique on XEVO GS-2 QTOf Waters mass spectrometer. FTIR measurements of all the compounds and dried gels (xerogels) were carried out using a Perkin-Elmer L120-00A spectrometer $\left(v_{\max }\right.$ in $\left.\mathrm{cm}^{-1}\right)$ using $\mathrm{KBr}$ cell and $\mathrm{KBr}$ pellets, respectively. Scanning electron microscopy (SEM) images were obtained on EVO LS-10 ZEISS instrument. Fluorescence and UV-vis studies were performed using Horiba Fluoromax 4C spectrofluorimeter and Shimadzu UV-2450 spectrophotometer, respectively.

\section{Synthesis}

\section{$N^{2}, N^{2}$-di(pyridin-3-yl) biphenyl-2,2'-dicarboxamide (1)}

To a stirred solution of biphenyl-2,2'-dicarboxylic acid $(0.87$ g, $3.59 \mathrm{mmol})$ in dry $\mathrm{CH}_{2} \mathrm{Cl}_{2}(20 \mathrm{~mL}), \mathrm{SOCl}_{2}(0.77 \mathrm{~mL}, 7.18$ $\mathrm{mmol}$ ) was added and the reaction mixture was refluxed for 10 h. On removal of excess $\mathrm{SOCl}_{2}$ under reduced pressure, compound $\mathbf{5}$ was obtained as solid mass, which was directly used in the next step. The symmetrical bisamide 1 was obtained by coupling of 3 -aminopyridine $(1.09 \mathrm{~g}, 10.77 \mathrm{mmol})$ with biphenyl-2,2'-dicarbonyl dichloride 5 in $60 \mathrm{~mL}$ dry $\mathrm{CH}_{2} \mathrm{Cl}_{2}$ followed by addition of triethylamine $(2.5 \mathrm{~mL})$ under nitrogen atmosphere. The reaction mixture was stirred for $12 \mathrm{~h}$. After completion of the reaction, solvent was removed under vacuum. The residual mass was extracted with $\mathrm{CHCl}_{3} / \mathrm{CH}_{3} \mathrm{OH}$ mixture $\left(30 \mathrm{~mL} \times 3\right.$ ). The organic layer was washed with $\mathrm{NaHCO}_{3}$ solution $(15 \mathrm{~mL} \times 3)$ and dried over anhydrous $\mathrm{Na}_{2} \mathrm{SO}_{4}$ and filtered. The filtrate was concentrated under reduced pressure. The crude mass was purified by column chromatography over silica gel using ethyl acetate : pet ether $(8: 1, V / V)$ as eluent to afford the desired diamide 1 in $64 \%$ yield $(0.9 \mathrm{~g})$, m.p. $92{ }^{\circ} \mathrm{C}$. ${ }^{1} \mathrm{H}$ NMR $\left(\mathrm{CDCl}_{3}\right.$ containing few drops of $d_{6}$-DMSO, $\left.400 \mathrm{MHz}\right) \delta$ : $10.45(\mathrm{~s}, 2 \mathrm{H}), 8.47(\mathrm{~s}, 2 \mathrm{H}), 8.16(\mathrm{~d}, 2 \mathrm{H}, \mathrm{J}=4 \mathrm{~Hz}), 7.93-7.90$ $(\mathrm{m}, 2 \mathrm{H}), 7.62-7.60(\mathrm{~m}, 2 \mathrm{H}), 7.34-7.30(\mathrm{~m}, 4 \mathrm{H}), 7.11-7.06$ $(\mathrm{m}, 4 \mathrm{H}) ;{ }^{13} \mathrm{C}$ NMR $\left(\mathrm{CDCl}_{3}\right.$ containing few drops of $d_{6}$-DMSO, $100 \mathrm{MHz}) \delta$ : 169.1, 144.9, 144.5, 138.9, 135.8, 135.3, 130.1, 129.5, 127.9, 127.6, 127.1, 123.4; FTIR (KBr) $v_{\max }: 3233$, 3173, 3117, 3052, 1654, 545, $1482 \mathrm{~cm}^{-1}$; HRMS (TOF MS ES ${ }^{+}$): Calcd for $(\mathrm{M}+\mathrm{H})^{+}$: 395.1508, Found: 395.1506.

\section{$N^{2}, N^{2}$-di(pyridin-2-yl) biphenyl-2,2'-dicarboxamide (2)}

To a stirred solution of biphenyl-2,2'-dicarboxylic acid (0.87 g, $3.59 \mathrm{mmol})$ in dry $\mathrm{CH}_{2} \mathrm{Cl}_{2}(20 \mathrm{~mL}), \mathrm{SOCl}_{2}(0.77 \mathrm{~mL}, 7.18$ $\mathrm{mmol}$ ) was added and the reaction mixture was refluxed for $10 \mathrm{~h}$. On removal of excess $\mathrm{SOCl}_{2}$ under reduced pressure, compound $\mathbf{5}$ was obtained as solid mass, which was directly used in the next step. The symmetrical bisamide 2 was obtained by coupling of 2-aminopyridine $(1.09 \mathrm{~g}, 10.77 \mathrm{mmol}$ ) with biphenyl-2,2'-dicarbonyl dichloride 5 in $60 \mathrm{~mL}$ dry $\mathrm{CH}_{2} \mathrm{Cl}_{2}$ followed by addition of triethylamine $(2.5 \mathrm{~mL})$ under nitrogen atmosphere. The reaction mixture was stirred for $12 \mathrm{~h}$. After completion of the reaction, solvent was removed under vacuum. The residual mass was dissolved in $10 \mathrm{~mL}$ of acetone followed by the addition of $100 \mathrm{~mL}$ of water and stirred for $30 \mathrm{~min}$. The $\mathrm{pH}$ of the medium was adjusted to $8-9$ by adding $\mathrm{NaHCO}_{3}$. Then, the precipitation was separated by filtration to have crude compound 2, which was purified by column chromatography over silica gel using ethyl acetate : pet ether $(6: 1, V / V)$ as eluent to afford the desired diamide 2 in $62 \%$ yield $(0.87 \mathrm{~g})$, m.p. $176{ }^{\circ} \mathrm{C} .{ }^{1} \mathrm{H} \mathrm{NMR}\left(\mathrm{CDCl}_{3}, 400 \mathrm{MHz}\right) \delta: 9.61(\mathrm{~s}, 2 \mathrm{H}), 8.16(\mathrm{~d}, 2 \mathrm{H}$, $J=8 \mathrm{~Hz}), 8.08(\mathrm{~d}, 2 \mathrm{H}, J=4 \mathrm{~Hz}), 7.32-7.71(\mathrm{~m}, 2 \mathrm{H})$, 7.64-7.59 (m, 2H), 7.41-7.39 (m, 4H), 7.26-7.21 (m, 2H), $6.94\left(\mathrm{dd}, 2 \mathrm{H}, J_{1}=8 \mathrm{~Hz}, \mathrm{~J}_{2}=4 \mathrm{~Hz}\right) ;{ }^{13} \mathrm{C} \mathrm{NMR}\left(\mathrm{CDCl}_{3}, 100 \mathrm{MHz}\right)$ $\delta:$ 168.6, 151.6, 147.6, 139.0, 138.2, 135.8, 130.3, 129.7, 128.0, 127.6, 119.6, 114.4; FTIR (KBr) v: 3235, 1676, 1575, 1524, 1430, $1366 \mathrm{~cm}^{-1}$; HRMS (TOF MS ES ${ }^{+}$): Calcd for $(\mathrm{M}+\mathrm{H})^{+}$: 395.1508, Found: 395.1526 . 


\section{$N^{2}, N^{2}$-di(pyridin-4-yl) biphenyl-2,2'-dicarboxamide (3)}

To a stirred solution of biphenyl-2,2'-dicarboxylic acid $(0.87$ g, $3.59 \mathrm{mmol})$ in dry $\mathrm{CH}_{2} \mathrm{Cl}_{2}(20 \mathrm{~mL}), \mathrm{SOCl}_{2}(0.77 \mathrm{~mL}, 7.18$ $\mathrm{mmol})$ was added and the reaction mixture was refluxed for 10 h. On removal of excess $\mathrm{SOCl}_{2}$ under reduced pressure, compound $\mathbf{5}$ was obtained as solid mass, which was directly used in the next step. The symmetrical bisamide $\mathbf{3}$ was obtained by coupling of 4-aminopyridine $(1.09 \mathrm{~g}, 10.77 \mathrm{mmol})$ with biphenyl-2,2'-dicarbonyl dichloride 5 in $60 \mathrm{~mL}$ dry $\mathrm{CH}_{2} \mathrm{Cl}_{2}$ followed by addition of triethylamine $(2.5 \mathrm{~mL})$ under nitrogen atmosphere. The reaction mixture was stirred for $12 \mathrm{~h}$. After completion of the reaction, solvent was removed under vacuum. The residual mass was extracted with $\mathrm{CHCl}_{3} / \mathrm{CH}_{3} \mathrm{OH}$ mixture $(30 \mathrm{~mL} \times 3)$. The organic layer was washed with $\mathrm{NaHCO}_{3}$ solution $(15 \mathrm{~mL} \times 3)$ and dried over anhydrous $\mathrm{Na}_{2} \mathrm{SO}_{4}$ and filtered. The filtrate was concentrated under reduced pressure. The crude mass was purified by column chromatography over silica gel using $10 \% \mathrm{MeOH}$ in ethyl acetate as eluent to afford the desired diamide 3 in $72 \%$ yield $(1.01 \mathrm{~g})$, m.p. $258{ }^{\circ} \mathrm{C}$. ${ }^{1} \mathrm{H}$ NMR $\left(\mathrm{CDCl}_{3}, 400 \mathrm{MHz}\right) \delta: 9.78(\mathrm{~s}, 2 \mathrm{H}), 8.36(\mathrm{~d}, 4 \mathrm{H}, J=8$ $\mathrm{Hz}), 7.68-7.65(\mathrm{~m}, 2 \mathrm{H}), 7.42-7.37(\mathrm{~m}, 8 \mathrm{H}), 7.13-7.09(\mathrm{~m}$, $2 \mathrm{H}) ;{ }^{13} \mathrm{C} \mathrm{NMR}\left(\mathrm{CDCl}_{3}, 100 \mathrm{MHz}\right) \delta: 169.6,150.1,145.5,138.7$, 135.3, 130.5, 129.6, 128.2, 127.5, 113.9; FTIR (KBr) v: 3285, 1658, 1592, 1528, 1415, $1366 \mathrm{~cm}^{-1}$; HRMS (TOF MS ES ${ }^{+}$): Calcd for $(\mathrm{M}+\mathrm{H})^{+}:$395.1508, Found: 395.1507.

\section{Biphenyl-3,3'-dicarboxylic acid bis-pyridin-3-ylamide (4)}

To a stirred solution of biphenyl-3,3'-dicarboxylic acid $(0.87$ $\mathrm{g}$, $3.59 \mathrm{mmol})$ in dry $\mathrm{CH}_{2} \mathrm{Cl}_{2}(20 \mathrm{~mL}), \mathrm{SOCl}_{2}(0.77 \mathrm{~mL}, 7.18$ $\mathrm{mmol}$ ) was added and the reaction mixture was refluxed for $8 \mathrm{~h}$. On removal of excess $\mathrm{SOCl}_{2}$ under reduced pressure, compound 6 was obtained as solid mass, which was directly used in the next step. The symmetrical bisamide 4 was obtained by coupling of 3-aminopyridine $(1.09 \mathrm{~g}, 10.77 \mathrm{mmol})$ with biphenyl-3,3'-dicarbonyl dichloride 6 in $60 \mathrm{~mL}$ dry $\mathrm{CH}_{2} \mathrm{Cl}_{2}$ followed by the addition of triethylamine $(2.5 \mathrm{~mL})$ under nitrogen atmosphere. The reaction mixture was stirred for $12 \mathrm{~h}$. After completion of the reaction, solvent was removed under vacuum. The residual mass was extracted with $\mathrm{CHCl}_{3} / \mathrm{CH}_{3} \mathrm{OH}$ mixture $(30 \mathrm{~mL} \times 3)$. The organic layer was washed with $\mathrm{NaHCO}_{3}$ solution $(15 \mathrm{~mL} \times 3)$ and dried over anhydrous $\mathrm{Na}_{2} \mathrm{SO}_{4}$ and filtered. The filtrate was concentrated under reduced pressure. The crude mass was purified by column chromatography over silica gel using ethyl acetate as eluent to afford the desired diamide 4 in $58 \%$ yield $\left(0.81\right.$ g), m.p. $266{ }^{\circ} \mathrm{C}$. ${ }^{1} \mathrm{H}$ NMR $\left(d_{6}\right.$-DMSO, $\left.400 \mathrm{MHz}\right) \delta: 10.64(\mathrm{~s}, 1 \mathrm{H}), 10.53(\mathrm{~s}, 1 \mathrm{H})$, $8.90-8.88(\mathrm{~m}, 2 \mathrm{H}), 8.49(\mathrm{~s}, 1 \mathrm{H}), 8.28-8.26(\mathrm{~m}, 3 \mathrm{H})$, 8.18-8.11 (m, 4H), 7.97-7.94 (m, 2H), $7.75(t, 1 \mathrm{H}, J=8 \mathrm{~Hz})$, $7.64(\mathrm{t}, 1 \mathrm{H}, J=8 \mathrm{~Hz}), 7.38-7.34(\mathrm{~m}, 2 \mathrm{H}) ;{ }^{13} \mathrm{C}$ NMR $\left(d_{6}\right.$-DMSO, $100 \mathrm{MHz}) \delta: 165.7,165.0,151.6,144.7,144.6,142.0,139.6$, 135.7, 135.6, 135.0, 130.8, 130.3, 129.8, 129.3, 127.5, 127.2, 126.1, 125.6, 123.5, 121.9 (appears unsymmetrical and some carbons overlap); FTIR (KBr) v: 3299, 1679, 1655, 1557, 1519, 1482, $1333 \mathrm{~cm}^{-1}$; HRMS (TOF MS ES ${ }^{+}$): Calcd for $(\mathrm{M}+\mathrm{H})^{+}$: 395.1508, Found: 395.1505.

\section{General procedure for gelation test}

The required amount of the compounds was firstly taken in pure organic solvents $(1 \mathrm{~mL})$, slightly warmed to dissolve and then cooled to room temperature to allow gelation. For semi aqueous solvents, compounds were firstly dissolved in the organic solvent and then water was added to it. Analyteresponsive behaviour of the compounds was investigated following the same method. In that case, all the guest analytes were taken in water. All the gels were tested via the usual inversion of vial method after $\sim 1 \mathrm{~h}$ of sample preparation. Samples of gel for SEM image was dried under vacuum and then coated with a thin layer of gold metal. The gel-to-sol transition temperature $\left(T_{\mathrm{g}}\right)$ was determined by the dropping ball method.

\section{General procedures of UV-vis and fluorescence titrations}

Stock solutions of the compounds were prepared in respective solvents in the concentration of $\sim 10^{-5} \mathrm{M}$. Stock solutions of the metal ions were also prepared in the same solvents in the concentration of $\sim 10^{-3} \mathrm{M}$. Solution of each compound $(2 \mathrm{~mL})$ was taken in the cuvette and to this solution different ions were individually added in different amounts. Upon addition of metal ions, the change in emission of the compound was recorded. The same stock solutions were used to perform the UV-vis titration experiment in the same way.

\section{Method for Job plot ${ }^{[104]}$}

The stoichiometry was determined by the continuous variation method (Job plot). In this method, solutions of host and guests of equal concentrations were prepared in respective solvent. Then host and guest solutions were mixed in different proportions maintaining a total volume of $3 \mathrm{~mL}$ of the mixture. The related compositions for host: guest $(V / V)$ were $3: 0,2.8$ : $0.2 ; 2.5: 0.5,2.2: 0.8,2: 1,1.8: 1.2,1.5: 1.5,1: 2,0.8: 2.2,0.5$ $2.5,0.2: 2.8$. All the prepared solutions were kept for $1 \mathrm{~h}$ with occasional shaking at room temperature. Then emission and absorbance of the solutions of different compositions were recorded. The concentration of the complex, i.e., [HG] was deduced using the equation $[\mathrm{HG}]=\Delta / / l_{0} \times[\mathrm{H}]$ or $[\mathrm{HG}]=\Delta A / A_{0} \times$ $[H]$, where $\Delta / / I_{0}$ and $\Delta A / A_{0}$ indicate the relative emission and absorbance intensities, respectively. $[H]$ corresponds the concentration of pure host. Mole fraction of the host $\left(X_{H}\right)$ was plotted against concentration of the complex [HG]. In the plot, mole fraction of the host, at which the concentration of the host-guest complex concentration [HG] is maximum, means the stoichiometry of the complex.

\section{Calculation of detection limit ${ }^{[103]}$}

The detection limit was calculated from fluorescence titration data. The emission of compound 1 was measured 5 times to measure the standard deviation of the blank. To have the slope, fluorescence intensities at $370 \mathrm{~nm}$ were plotted as concentrations of $\mathrm{Ag}^{+}$. The detection limit was calculated using the equation: detection limit $=3 \sigma / k$, where $\sigma$ is the standard deviation of blank measurement and $\mathrm{k}$ is the slope.

\section{Results and Discussion}

Compounds $\mathbf{1}-\mathbf{4}$ were obtained according to the Scheme 1. Simple coupling of biphenyl-2,2'-diacid dichloride 5 with 3-, 2and 4-aminopyridines in the presence of $\mathrm{Et}_{3} \mathrm{~N}$ in dry $\mathrm{CH}_{2} \mathrm{Cl}_{2}$ at room temperature resulted in formation of compounds 1, 2 and 3 , respectively (Scheme 1). Whereas, under similar reaction conditions, treatment of biphenyl-3,3'-diacid dichloride 6 with

Scheme 1 Synthesis of compounds $1-4$

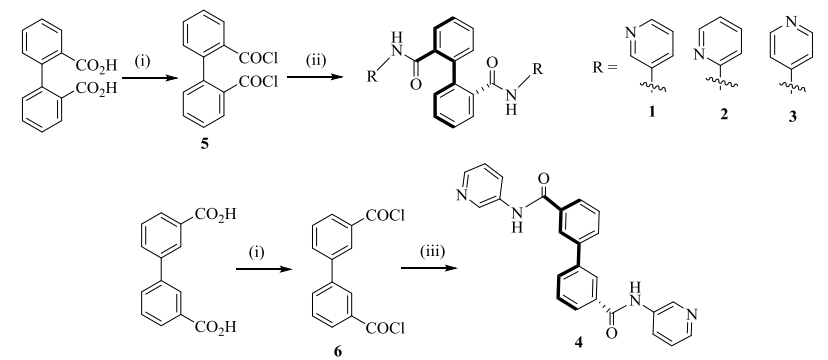

Reagents and conditions: (i) $\mathrm{SOCl}_{2}$, dry $\mathrm{CH}_{2} \mathrm{Cl}_{2}$, reflux, $10 \mathrm{~h}$; (ii) 2-, 3-, or 4-amino pyridine, $\mathrm{Et}_{3} \mathrm{~N}$, dry $\mathrm{CH}_{2} \mathrm{Cl}_{2}$, r.t., $12 \mathrm{~h}$; (iii) 3-amino pyridine, $\mathrm{Et}_{3} \mathrm{~N}$, dry $\mathrm{CH}_{2} \mathrm{Cl}_{2}$, r.t., 12 h. 


\section{Report}

3-aminopyridine introduced compound $\mathbf{4}$ in appreciable yield. All the compounds were characterized by usual spectroscopic techniques.

Structural analysis reveals that compounds $\mathbf{1}-\mathbf{4}$ possess bispyridyl amide motifs around the aromatic biphenyl spacer that imparts rigidity and conformational flexibility. ${ }^{[39]}$ In the structures, while the amide $\mathrm{NHs}$ act as hydrogen bond donors, the pyridyl motifs serve as hydrogen bond acceptors. Therefore, the molecules may assume different conformations and as such, different hydrogen bonding characteristics in solution. ${ }^{[38,39]}$ Considering such different attributes, initially the gelation abilities of the compounds $\mathbf{1 - 4}$ were examined in a wide range of protic and aprotic solvents with different polarities and coordination abilities. The results are summarized in Table 1S. It was observed that all the compounds showed non-gelation behaviours and remained either as soluble or produced precipitation in most of the solvents. However, in THF, 1,4-dioxan, DMF and DMSO, compound $\mathbf{1}$ formed white coloured gel in the presence of aqueous $\mathrm{Ag}^{+}$ion. In DMSO : $\mathrm{H}_{2} \mathrm{O}(1: 2, \mathrm{~V} / \mathrm{V})$, it formed gel with lower minimum gelation concentration of $3.9 \mathrm{mg} / \mathrm{mL}$ (Figure 2). Under identical conditions, the rest of the compounds behaved as a non gelator. Hence, comparison of aggregation behaviours of compounds $1-3$ highlights the positional role of pyridine ring nitrogen with respect to the biphenyl ring, which controls the self-aggregation of the molecules in the presence of $\mathrm{Ag}^{+}$ions. Moreover, the contrasting behaviours of compounds 1 and 4 in presence of $\mathrm{Ag}^{+}$ions emphasize that the gelation abilities of these molecules depend significantly on the hydrogen bonding interactions of the amide moieties, coupled to the isomeric spacers.

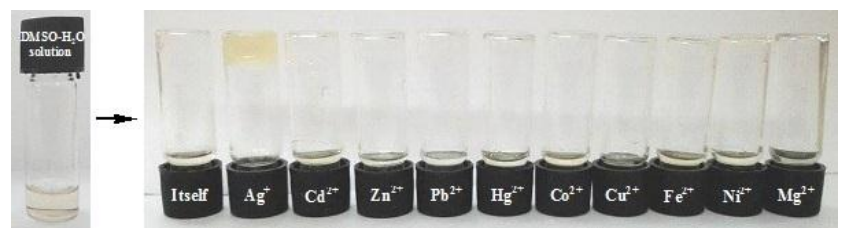

Figure 2 Photograph showing the phase changes of 1 (3.9 $\mathrm{mg} / \mathrm{mL})$ in DMSO : $\mathrm{H}_{2} \mathrm{O}(1: 2, V / V)$ in presence of 2 equiv. amounts of different metal ions $\left[c=0.4 \mathrm{M}\right.$ in $\mathrm{H}_{2} \mathrm{O}$ as perchlorate salt] after $1 \mathrm{~h}$.

We also investigated the effect of other metal ions on gelation of 1 (Figure 2). Interestingly, except $\mathrm{Ag}^{+}$, other metal ions considered in the study were found to be futile in bringing gelation. The presence of other metal ions like $\mathrm{Cu}^{2+}, \mathrm{Hg}^{2+}, \mathrm{Cd}^{2+}$, $\mathrm{Zn}^{2+}, \mathrm{Co}^{2+}, \mathrm{Ni}^{2+}, \mathrm{Pb}^{2+}, \mathrm{Mg}^{2+}$ and $\mathrm{Fe}^{2+}$ under similar conditions produced either precipitate or solution. These results indicated the metal responsive behaviour of $\mathbf{1}$ and validated the visual sensing of $\mathrm{Ag}^{+}$. In the study, minimum 2 equiv. amounts of $\mathrm{Ag}^{+}$ ion was necessary to form the thick gel at a gelator concentration of $3.9 \mathrm{mg} / \mathrm{mL}$.

The gel was thermo reversible and upon heating was transformed into clear solution, which upon cooling again to room temperature caused reappearance of the gel (Figure 3a). The thermal stability of the gel was studied in DMSO : $\mathrm{H}_{2} \mathrm{O}$ solvent system. At minimum gelation concentration of 3.9 $\mathrm{mg} / \mathrm{mL}$, the gel melting temperature $\left(T_{\mathrm{g}}\right)$ was recorded as $52^{\circ} \mathrm{C}$ and a sharp increase in $T_{\mathrm{g}}$ value was observed with increase in gelator's concentration (Figure $3 b$ ). Similar gel-to-sol phase transformation was noticed in presence of silver chelating agent (Figure 1S). Initially, the silver metallogel of 1 was treated with external chemical stimuli like $\mathrm{Cl}^{-}$ion. The addition of 2 equiv. amounts of $\mathrm{KCl}$ (in water) on the top of the gel at room temperature scavenged the interlinked $\mathrm{Ag}^{+}$ions from the gel matrix

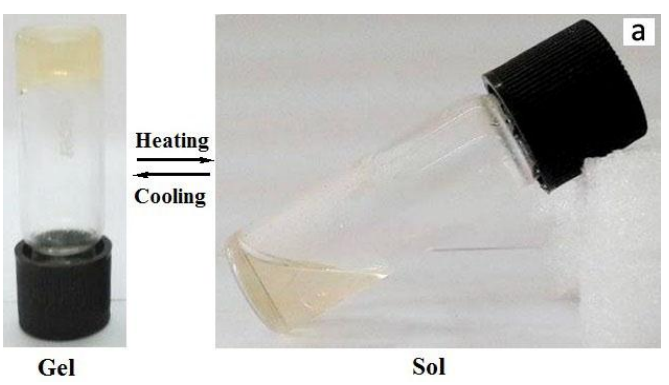

b

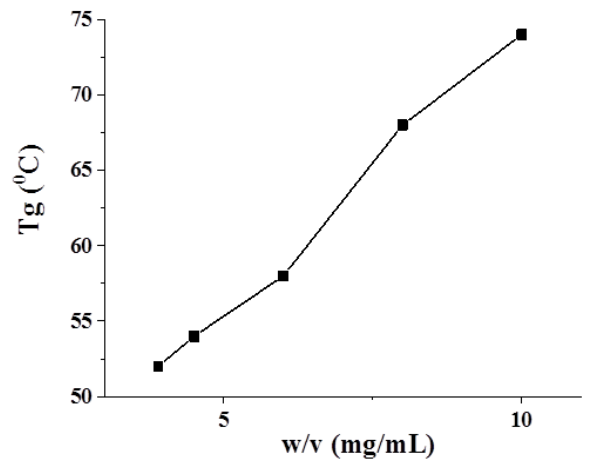

Figure 3 (a) Pictorial representation of the thermo reversibility of the DMSO : $\mathrm{H}_{2} \mathrm{O}(1: 2, V / V)$ gels of $1(3.9 \mathrm{mg} / \mathrm{mL})$ in presence of $\mathrm{Ag}^{+}$(2 equiv.). (b) Variation of gel melting temperature $\left(T_{\mathrm{g}}\right)$ with increasing concentration of gelator 1 in DMSO : $\mathrm{H}_{2} \mathrm{O}$ $(1: 2, V / V)$ in presence of 2 equiv. amounts of $\mathrm{Ag}^{+}$.

and ruptured the gel to sol (within $1 \mathrm{~h}$ ) with white precipitate of $\mathrm{AgCl}$. Further addition of $\mathrm{Ag}^{+}$to the $\mathrm{Cl}^{-}$-induced broken gel resulted in reappearance of the gel after $30 \mathrm{~min}$.

The viscoelastic properties of $\mathrm{Ag}^{+}$-gel of 1 was characterised by rheological measurements, in which the storage modulus G' and the loss modulus G" were measured as a function of strain and frequency (Figures $4 \mathrm{a}$ and $4 \mathrm{~b}$ ). In strain sweep, a nonlinear response of both G' and G" was observed with the applied strain amplitude at a fixed frequency ( $\omega=10 \mathrm{rad} / \mathrm{s})$. With gradual increase in the applied stress, both G' and G" were deviated from linearity at $10 \%$ of strain (critical strain) indicating that the gel started to collapse, after which a sharp fall of both 'G' and G' values was observed. The gel was completely destroyed beyond a strain of $24 \%$ (crossover point). In a frequency sweep experiment, at a fixed strain of $1 \%$, both $G^{\prime}$ and 'G' were frequency invariant over the entire range studied and the values of $G^{\prime}$ were around seven times greater than $G$ ' at any frequency, signifying dominant elastic character of the metallogel.

The morphology of the metallogel was studied by SEM images that exhibited layer by layer stacking of closely spaced flakes like matrices (Figures $4 \mathrm{c}$ and $4 \mathrm{~d}$ ). To our belief, molecules of compound $\mathbf{1}$ under the influence of intermolecular hydrogen bonding of the amide groups and silver coordination involving two pyridyl units of two different gelator molecules adopt a linear binding geometry that undergoes stacking as proposed in Figure 5.

To support our proposition of interaction, FTIR spectra of compound $\mathbf{1}$ in its amorphous and gel states were analyzed. Compound 1 in amorphous state showed the stretching for amide $\mathrm{C}=\mathrm{O}$ at $1684 \mathrm{~cm}^{-1}$ as sharp signal and it was shifted to 

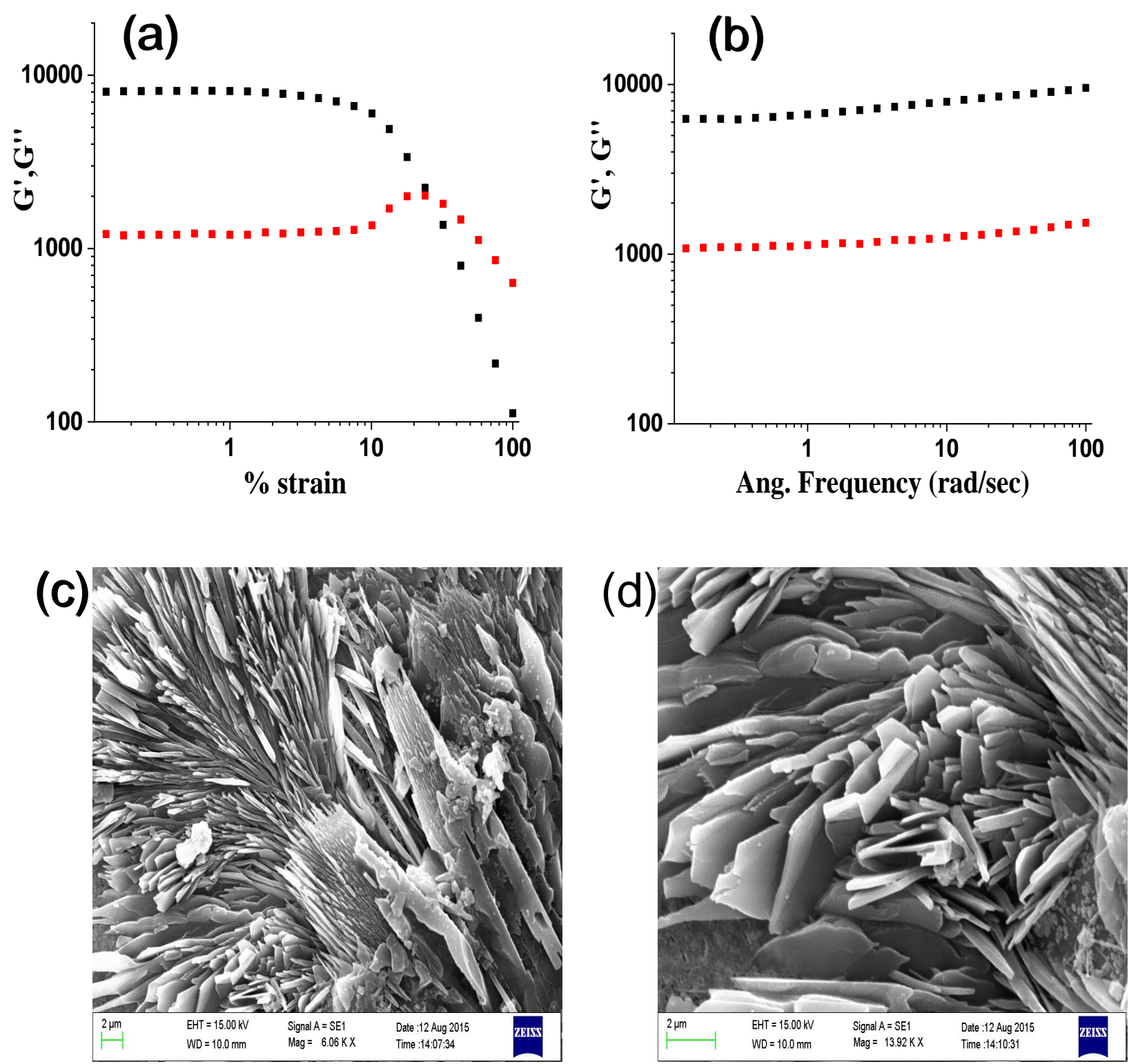

Figure 4 (a) Strain and (b) frequency sweeps of the $\mathrm{Ag}^{+}$-gel of $1(3.9 \mathrm{mg} / \mathrm{mL})$ prepared from DMSO : $\mathrm{H}_{2} \mathrm{O}(1: 2, V / \mathrm{V})$. In both cases, the black symbols represent $G^{\prime}$, red symbols $G^{\prime \prime}$. (c) and (d) represent the SEM images of xerogel of compound 1 (3.9 mg/mL) with $\mathrm{Ag}^{+}$prepared from DMSO : $\mathrm{H}_{2} \mathrm{O}(1: 2, \mathrm{~V} / \mathrm{V})$. In all cases, $\left[\mathrm{Ag}^{+}\right]=2$ molar equiv. with respect to 1 .
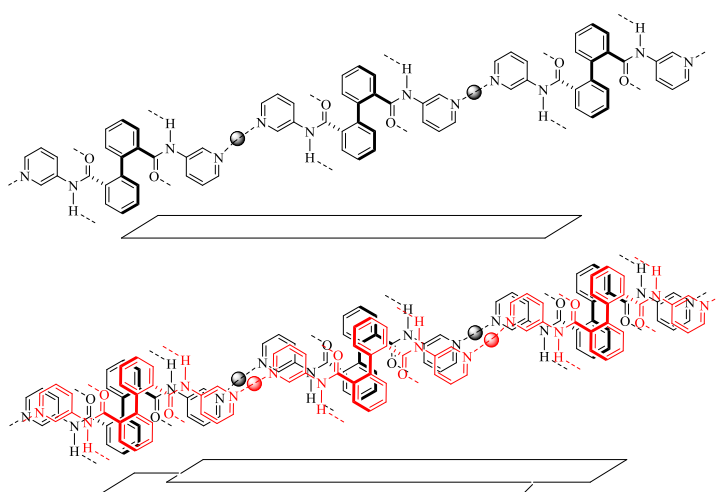

Figure 5 Suggested mode of interaction of compound 1 with $\mathrm{Ag}^{+}$to form 3D-network in solution.
$1646 \mathrm{~cm}^{-1}$ with broadening in the gel state (Figure 6a). Moreover, stretching frequency of the amide $\mathrm{NH}$ of compound 1 moved to the higher region by 188 units in the gel states. These findings undoubtedly corroborate the important roles of metal chelation and hydrogen bonding during gelation, respectively. In order to understand the metal ligand interactions in detail, we further recorded ${ }^{1} \mathrm{H}$ NMR of compound 1 itself and with $\mathrm{Ag}^{+}$in $\mathrm{CDCl}_{3}$ containing few drops of $d_{6}$-DMSO (Figure 2S). In general, metal ion coordination leads to downfield chemical shift of the aromatic ring protons. ${ }^{[39,48,58,103]}$ However, this is not always true for metal ion-induced self-assembled systems. ${ }^{[21,30,38,56,59]}$ In case of metallogels, the chemical shift of the protons depends entirely upon the self-assembly pattern established after metal coordination. In addition, metal ion coordination is not the only determining factor for showing the chemical shift of the corresponding ring protons, other non-covalent interactions like 
(a)

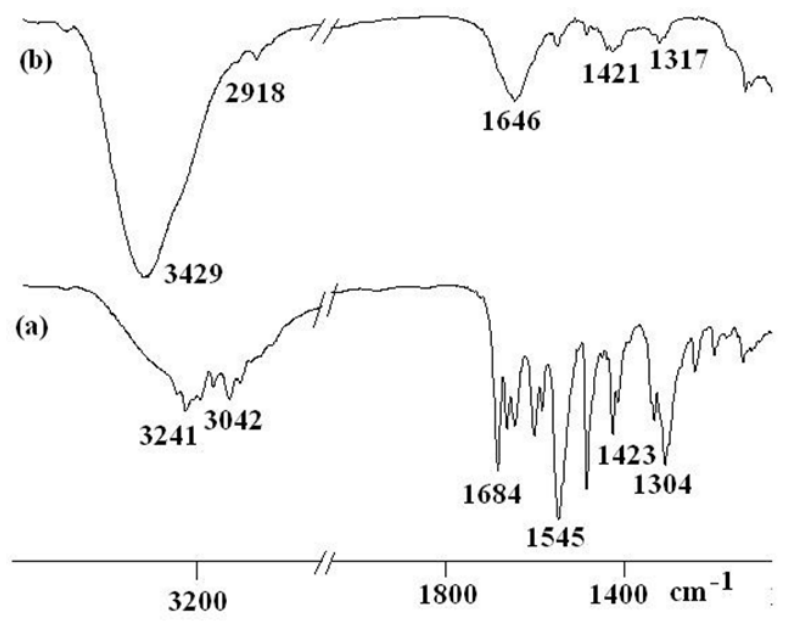

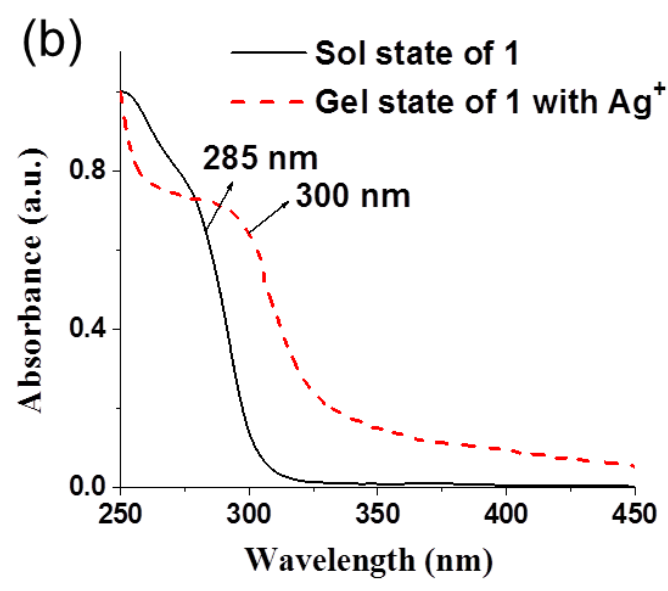

(c)

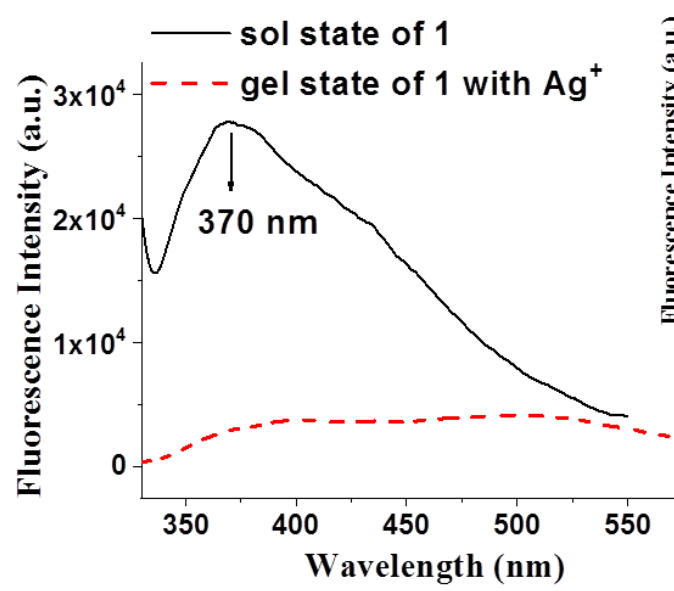

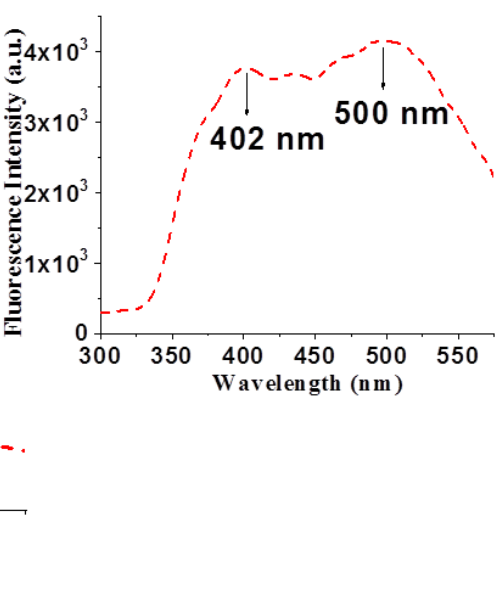

Figure 6 Partial FTIR spectra of 1 in (i) amorphous and (ii) gel states. Comparison of UV-vis (b) and fluorescence (c) spectra of compound $\mathbf{1}$ in the sol and gel states; [Inset: emission spectra of compound $\mathbf{1}$ in gel state]. In all cases, concentration of $\mathbf{1}$ is 3.9 $\mathrm{mg} / \mathrm{mL}$. The gel was prepared with $\mathrm{Ag}^{+}$(2 molar equiv. with respect to 1). Solvent is DMSO : $\mathrm{H}_{2} \mathrm{O}(1: 2, \mathrm{~V} / \mathrm{V})$.

hydrogen bonding, aromatic stacking, and so on, which regulate the growth of the assembly, while working tandem also influences chemical shift of the protons. ${ }^{[21,30,38,56,59]}$ In ${ }^{1} \mathrm{H}$ NMR of compound 1 with 2 equiv. amounts of $\mathrm{Ag}^{+}$, the upfield chemical shift of the amide $\mathrm{NH}_{\mathrm{a}}(\Delta \delta 0.04)$ including all aromatic protons $(\Delta \delta 0.04-0.06)$ indicated metal-ligand interaction (Figure $2 \mathrm{~S}) .{ }^{[30,38]}$ These results signify that, for ligand $\mathbf{1}$, metal binding followed by intermolecular hydrogen bonding simultaneously plays a crucial role during gelation.

To examine the key role of $\pi-\pi$ stacking interactions exerted by biphenyl units, UV-vis and emission spectra of compound $\mathbf{1}$ in sol and gel states were compared. A strong absorption band at $300 \mathrm{~nm}$ in UV-vis spectrum of compound 1 in the gel state (Figure $6 b$ ) with respect to the sol state corroborated the aggregation-induced planarization of the biphenyl unit that extends the effective $\pi$-conjugation length. ${ }^{[39,105]}$ On the other hand, in emission spectra, it exhibited aggregation-induced quenching, where $32 \mathrm{~nm}$ red shifted band in the gel state as compared to sol state was observed (Figure $6 c$ ). Additionally, the gel state showed a new band at $500 \mathrm{~nm}$ with slightly higher intensity. This indicated that the gel formation occurred not only due to metal coordination but also the $\pi-\pi$ stacking of the biphenyl units ${ }^{[39,105]}$ played a significant role during aggregation process.
In order to correlate the selective gelation of compound $\mathbf{1}$ by $\mathrm{Ag}^{+}$, solution phase interactions studies were conducted. We performed UV-vis and fluorescence titrations of $1\left(c=2.5 \times 10^{-5}\right.$ M) in DMSO : $\mathrm{H}_{2} \mathrm{O}(1: 9, V / V)$. In fluorescence, compound 1 initially showed emission band at $370 \mathrm{~nm}$ upon excitation at 290 $\mathrm{nm}$. Figure $7 \mathrm{a}$ represents the change in fluorescence ratio of compound 1 at $370 \mathrm{~nm}$ in the presence of 6 equiv. amounts of metal ions and highlights the sensitivity towards $\mathrm{Ag}^{+}$over the other metal ions taken in the study. During titration, while intensity of the emission at $370 \mathrm{~nm}$ underwent significant enhancement only in the presence of $\mathrm{Ag}^{+}$ions (Figures $7 \mathrm{~b}$ and $3 S$ ), other metal ions gave a negligible effect on emission of compound 1.

$\mathrm{Ag}^{+}$-induced greater enhancing of emission at $370 \mathrm{~nm}$ even in the presence of other metal ions corroborated the selectivity of compound $\mathbf{1}$ towards silver ions (Figure 8a), where other metals in the study were found to be noninterfering. In this process, the detection limits ${ }^{[103]}$ for $\mathrm{Ag}^{+}$was determined to be $2.64 \times 10^{-6} \mathrm{M}$ (Figure 4S). The binding constant ${ }^{[106]}$ values were found to be $K_{1}=(1.25 \pm 0.48) \times 10^{4} \mathrm{M}^{-1}$ and $K_{2}=(4.94 \pm 1.83)$ $\times 10^{4} \mathrm{M}^{-1}$, respectively, with $1: 2\left(1: \mathrm{Ag}^{+}\right)$stoichiometries ${ }^{[104]}$ (Figures $5 \mathrm{~S}$ and $6 \mathrm{~S}$ ).

In UV-vis titration of compound 1, in presence of $\mathrm{Ag}^{+}$ion, the intensity of the absorption peak at $290 \mathrm{~nm}$ was increased 


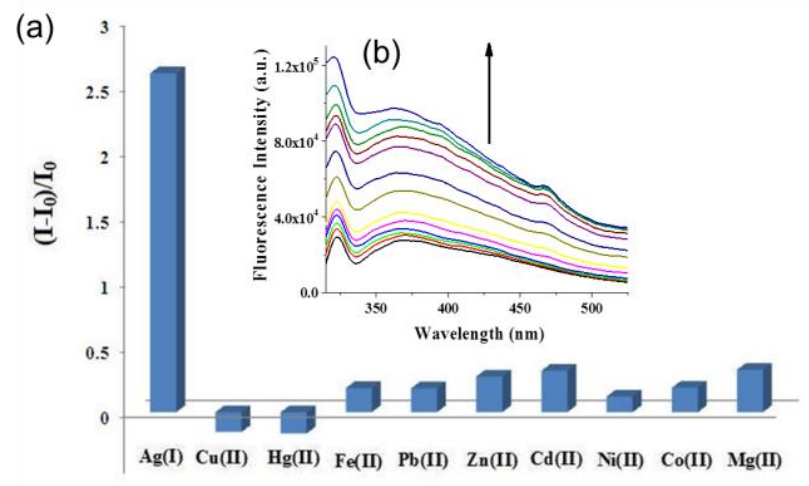

Figure 7 (a) Change in fluorescence ratio $\left(\lambda_{\mathrm{ex}}=290 \mathrm{~nm}\right)$ of compound $1\left(c=2.5 \times 10^{-5} \mathrm{M}\right)$ at $370 \mathrm{~nm}$ upon addition of 6 equiv. amounts of metal ions $\left(c=1.0 \times 10^{-3} \mathrm{M}\right)$ and $(\mathrm{b})$ change in emission of compound $1\left(c=2.5 \times 10^{-5} \mathrm{M}\right)$ upon addition of 6 equiv. amount of $\mathrm{Ag}^{+}$in DMSO : $\mathrm{H}_{2} \mathrm{O}(1: 9, \mathrm{~V} / \mathrm{V})$.

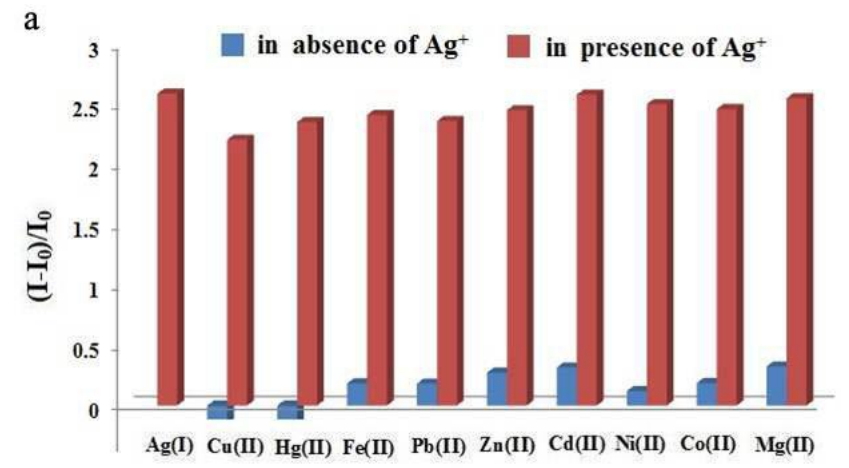

b

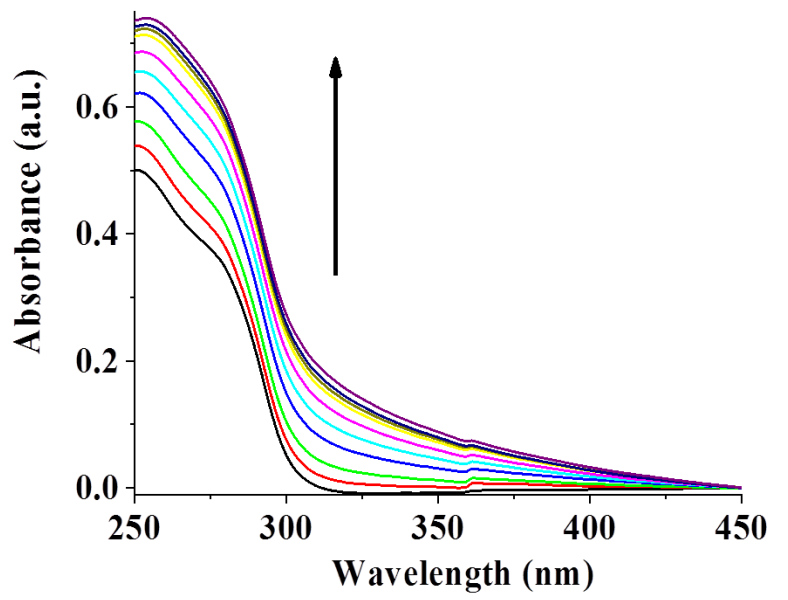

Figure 8 (a) Fluorescence response of compound 1 ( $c=2.50$ $\times 10^{-5} \mathrm{M}$ ) upon addition of 6 equiv. amounts of $\mathrm{Ag}^{+}$ions to the solution of 1 containing other metal ions in 6 equiv. amounts in DMSO : $\mathrm{H}_{2} \mathrm{O}(1: 9, V / V)$. (b) Change in absorbance of compound $1\left(C=2.50 \times 10^{-5} \mathrm{M}\right)$ upon addition of 6 equiv. amount of $\mathrm{Ag}^{+}\left(c=1.0 \times 10^{-3} \mathrm{M}\right)$ in DMSO : $\mathrm{H}_{2} \mathrm{O}(1: 9, \mathrm{~V} / \mathrm{V})$.

significantly, where other metal ions resulted in negligible change in the absorption spectra (Figures $8 \mathrm{~b}$ and $7 \mathrm{~S}$ ). From Job method, ${ }^{[104]} 1: 2$ ligand-metal interaction was confirmed, and the binding constant values ${ }^{[106]}$ were calculated to be $K_{1}=$ $(5.02 \pm 3.81) \times 10^{3} \mathrm{M}^{-1}$ and $K_{2}=(1.02 \pm 0.76) \times 10^{5} \mathrm{M}^{-1}$, respectively (Figures $5 S$ and $6 S$ ).

\section{Conclusions and Perspectives}

In conclusion, a series of pyridyl bisamides coupled to biphenyl skeleton have been designed and synthesized. Out of the bisamides $\mathbf{1 - 4}$, only the compound $\mathbf{1}$ is established as a potential gelator that forms gel in presence of $\mathrm{Ag}^{+}$ions and validates its visual sensing. The nongelation behaviour of other derivatives 2 and $\mathbf{3}$ highlights the positional role of pyridine ring nitrogen with respect to the biphenyl ring during self-aggregation in the presence of $\mathrm{Ag}^{+}$ions. In relation to this, different behaviours of the ortho and meta derivatives 1 and 4, respectively, towards gelation in presence of $\mathrm{Ag}^{+}$ions is interesting. The findings signify that the gelation abilities of these molecules depend significantly on the hydrogen bonding interactions of the amide moieties around the isomeric biphenyl spacers. Spectroscopic studies confirm that the metal coordination as well as the hydrogen bonding involving the amide $\mathrm{NHs}$ of compound 1 play a crucial role in establishing the gel network in solution. Compound 1 also selectively recognizes $\mathrm{Ag}^{+}$ions fluorimetrically in a turn-on mode in solution. Exploration of biphenyl-based gelators in selective metal ion recognition is rare (as most of them suffered interference from other metal ions) in the literature (Table 2S), and hence, compound $\mathbf{1}$ draws attention.

\section{Acknowledgement}

S. P. thanks the Royal Society, UK and SERB of India for a Newton International Fellowship. K. G. thanks SERB, DST, New Delhi, for financial support (No. EMR/2016/008005/OC).

\section{Author Contributions}

Authors have equal contribution in the manuscript.

\section{Author Information}

\section{ORCID}

S. P.: 0000-0002-5082-5196

K. G.: 0000-0003-1236-8139

\section{Supporting Information}

Figures show the changes in emission and absorption spectra, binding curves, detection limit, NMR and mass studies, copies of ${ }^{1} \mathrm{H}$ NMR, ${ }^{13} \mathrm{C}$ NMR and HRMS spectra.

\section{Conflict of Interest}

The authors declare no conflict of interest.

Copyright () 2020 Santanu Panja, Kumaresh Ghosh. This article is an open access article distributed under the terms and conditions of the Creative Commons Attribution (CC BY) license (http://creativecommons.org/licenses/by/4.0/). The use, distribution or reproduction in other forums is permitted, provided the original author(s) or licensor are credited and that the original publication in this journal is cited, in accordance with accepted academic practice. No use, distribution or reproduction is permitted which does not comply with these terms.

\section{References}

[1] Kuosmanen, R.; Rissanen, K.; Sievänen, E. Steroidal supramolecular metallogels. Chem. Soc. Rev. 2020, 49, 1977-1998.

[2] Dastidar, P. Designing Supramolecular Gelators: Challenges, Frustrations, and Hopes. Gels 2019, 5, 15.

[3] Mehwish, N.; Dou, X.; Zhao, Y.; Feng, C.-L. Supramolecular fluorescent hydrogelators as bio-imaging probes. Mater. Horiz. 2019, 6, 14-44. 
[4] Li, J.; Geng, L.; Wang, G.; Chu, H.; Wei, H. Self-Healable Gels for Use in Wearable Devices. Chem. Mater. 2017, 29, 8932-8952.

[5] Li, J.; Xing, R.; Bai, S.; Yan, X. Recent advances of self-assembling peptide-based hydrogels for biomedical applications. Soft Matter 2019, 15, 1704-1715.

[6] Echeverria, C.; Fernandes, S. N.; Godinho, M. H.; Borges, J. P.; Soares, P. I. P. Functional Stimuli-Responsive Gels: Hydrogels and Microgels. Gels 2018, 4, 54.

[7] Deen, G. R.; Loh, X. J. Stimuli-Responsive Cationic Hydrogels in Drug Delivery Applications. Gels 2018, 4, 13.

[8] Jones, C. D.; Steed, J. W. Gels with sense: supramolecular materials that respond to heat, light and sound. Chem. Soc. Rev. 2016, 45, 6546-6596.

[9] Díaz Díaz, D.; Kühbeck, D.; Koopmans, R. J. Stimuli-responsive gels as reaction vessels and reusable catalysts. Chem. Soc. Rev. 2011, 40, 427-448.

[10] Heidarian, P.; Kouzani, A. Z.; Kaynak, A.; Paulino, M.; Nasri-Nasrabadi, B. Dynamic Hydrogels and Polymers as Inks for Three-Dimensional Printing. ACS Biomater. Sci. Eng. 2019, 5, 2688-2707.

[11] Sato, K.; Hendricks, M. P.; Palmer, L. C.; Stupp, S. I. Peptide supramolecular materials for therapeutics. Chem. Soc. Rev. 2018, 47, 7539-7551.

[12] Picchioni, F.; Muljana, H. Hydrogels Based on Dynamic Covalent and Non Covalent Bonds: A Chemistry Perspective. Gels 2018, 4, 21.

[13] Mayr, J.; Saldías, C.; Díaz Díaz, D. Release of small bioactive molecules from physical gels. Chem. Soc. Rev. 2018, 47, 1484-1515.

[14] Liu, M.; Ouyang, G.; Niu, D.; Sang, Y. Supramolecular gelatons: towards the design of molecular gels. Org. Chem. Front. 2018, 5, 2885-2900.

[15] Bolla, P. K.; Rodriguez, V. A.; Kalhapure, R. S.; Kolli, C. S.; Andrews, S.; Renukuntla, J. A review on $\mathrm{pH}$ and temperature responsive gels and other less explored drug delivery systems. $J$ Drug Deliv. Sci. Technol. 2018, 46, 416-435.

[16] Wu, H.; Zheng, J.; Kjøniksen, A.-L.; Wang, W.; Zhang, Y.; Ma, J., Metallogels: Availability, Applicability, and Advanceability. Adv. Mater. 2019, 31, 1806204

[17] Li, J.; Wong, W.-Y.; Tao, X.-m. Recent advances in soft functional materials: preparation, functions and applications. Nanoscale 2020 , 12, 1281-1306.

[18] McConnell, A. J.; Wood, C. S.; Neelakandan, P. P.; Nitschke, J. R. Stimuli-Responsive Metal-Ligand Assemblies. Chem. Rev. 2015, 115, 7729-7793.

[19] Segarra-Maset, M. D.; Nebot, V. J.; Miravet, J. F.; Escuder, B. Control of molecular gelation by chemical stimuli. Chem. Soc. Rev. 2013, 42, 7086-7098.

[20] Panja, S.; Adams, D. J. Gel to gel transitions by dynamic self-assembly. Chem. Commun. 2019, 55, 10154-10157.

[21] Panja, A.; Ghosh, K. Triazole-amide isosteric pyridine-based supramolecular gelators in metal ion and biothiol sensing with excellent performance in adsorption of heavy metal ions and picric acid from water. New J. Chem. 2019, 43, 934-945.

[22] Draper, E. R.; Adams, D. J. Photoresponsive gelators. Chem. Commun. 2016, 52, 8196-8206.

[23] Dhiman, S.; Jalani, K.; George, S. J. Redox-Mediated, Transient Supramolecular Charge-Transfer Gel and Ink. ACS Appl. Mater. Interfaces 2020, 12, 5259-5264.

[24] Chu, C.-W.; Stricker, L.; Kirse, T. M.; Hayduk, M.; Ravoo, B. J. Light-Responsive Arylazopyrazole Gelators: From Organic to Aqueous Media and from Supramolecular to Dynamic Covalent Chemistry. Chem. Eur. J 2019, 25, 6131-6140.

[25] Frisch, H.; Besenius, P. pH-Switchable Self-Assembled Materials. Macromol. Rapid Commun. 2015, 36, 346-363.

[26] Panja, S.; Patterson, C.; Adams, D. J. Temporally-Programmed
Transient Supramolecular Gels. Macromol. Rapid Commun. 2019, 40, 1900251

[27] Panja, S.; Dietrich, B.; Adams, D. J. Chemically Fuelled SelfRegulating Gel-to-Gel Transition. ChemSystemsChem 2020, 2, e1900038.

[28] Zacharias, S. C.; Ramon, G.; Bourne, S. A. Supramolecular metallogels constructed from carboxylate gelators. Soft Matter 2018, 14, 4505-4519.

[29] Li, Y.-F.; Li, Z.; Lin, Q.; Yang, Y.-W. Functional supramolecular gels based on pillar[ $n]$ arene macrocycles. Nanoscale 2020, 12, 2180-2200.

[30] Panja, A.; Ghosh, K., Diaminomalenonitrile-decorated cholesterolbased supramolecular gelator: aggregation, multiple analyte (hydrazine, $\mathrm{Hg}^{2+}$ and $\mathrm{Cu}^{2+}$ ) detection and dye adsorption. New J. Chem. 2018, 42, 13718-13725.

[31] Auletta, J. T.; LeDonne, G. J.; Gronborg, K. C.; Ladd, C. D.; Liu, H. Clark, W. W.; Meyer, T. Y. Stimuli-Responsive Iron-Cross-Linked Hydrogels That Undergo Redox-Driven Switching between Hard and Soft States. Macromolecules 2015, 48, 1736-1747.

[32] Yao, H.; Wang, J.; Song, S.-S.; Fan, Y.-Q.; Guan, X.-W.; Zhou, Q.; Wei, T.-B.; Lin, Q.; Zhang, Y.-M. A novel supramolecular AIE gel acts as a multi-analyte sensor array. New J. Chem. 2018, 42, $18059-18065$.

[33] Chen, J.; Wang, T.; Liu, M. A hydro-metallogel of an amphiphilic I-histidine with ferric ions: shear-triggered self-healing and shrinkage. Inorg. Chem. Front. 2016, 3, 1559-1565.

[34] Schneider, H.-J. Chemomechanical Gels-Actuators and Sensors. In Chemoresponsive Materials: Stimulation by Chemical and Biological Signals, Chapter 3, The Royal Society of Chemistry, UK, 2015, pp. 44-66.

[35] Ghosh, D.; Lebedytè, I.; Yufit, D. S.; Damodaran, K. K.; Steed, J. W., Selective gelation of $\mathrm{N}$-(4-pyridyl)nicotinamide by copper(ii) salts. CrystEngComm 2015, 17, 8130-8138.

[36] Lin, Q.; Gong, G.-F.; Fan, Y.-Q.; Chen, Y.-Y.; Wang, J.; Guan, X.-W.; Liu, J.; Zhang, Y.-M.; Yao, H.; Wei, T.-B. Anion induced supramolecular polymerization: a novel approach for the ultrasensitive detection and separation of $\mathrm{F}^{-}$. Chem. Commun. 2019, 55, 3247-3250.

[37] Li, Y.; Young, D. J.; Loh, X. J. Fluorescent gels: a review of synthesis, properties, applications and challenges. Mater. Chem. Front. 2019, 3, 1489-1502.

[38] Panja, S.; Ghosh, S.; Ghosh, K. Pyridine/pyridinium symmetrical bisamides as functional materials: aggregation, selective sensing and drug release. New J. Chem. 2018, 42, 6488-6497.

[39] Panja, S.; Bhattacharya, S.; Ghosh, K. Pyridine coupled mono and bisbenzimidazoles as supramolecular gelators: selective metal ion sensing and ionic conductivity. Mater. Chem. Front. 2018, 2, 385-395.

[40] Feng, J.; Zhang, H. Hybrid materials based on lanthanide organic complexes: a review. Chem. Soc. Rev. 2013, 42, 387-410.

[41] Zhang, W.; Gao, C. Morphology transformation of self-assembled organic nanomaterials in aqueous solution induced by stimuli-triggered chemical structure changes. J. Mat. Chem. A 2017, 5, 16059-16104.

[42] Sutar, P.; Maji, T. K. Coordination polymer gels: soft metal-organic supramolecular materials and versatile applications. Chem. Commun. 2016, 52, 8055-8074.

[43] Dhibar, S.; Dey, A.; Majumdar, S.; Ghosh, D.; Mandal, A.; Ray, P. P.; Dey, B. A supramolecular Cd(ii)-metallogel: an efficient semiconductive electronic device. Dalton Trans. 2018, 47, 17412-17420.

[44] Liu, J.; Fan, Y.-Q.; Song, S.-S.; Gong, G.-F.; Wang, J.; Guan, X.-W.; Yao, H.; Zhang, Y.-M.; Wei, T.-B.; Lin, Q. Aggregation-Induced Emission Supramolecular Organic Framework (AIE SOF) Gels Constructed from Supramolecular Polymer Networks Based on Tripodal Pillar[5]arene for Fluorescence Detection and Efficient Removal of Various Analytes. ACS Sustain. Chem. Eng. 2019, 7, 
11999-12007.

[45] Liu, J.; Fan, Y.-Q.; Zhang, Q.-P.; Yao, H.; Zhang, Y.-M.; Wei, T.-B.; Lin, Q. Super metal hydrogels constructed from a simple tripodal gelator and rare earth metal ions and its application in highly selective and ultrasensitive detection of histidine. Soft Matter 2019, 15, 999-1004

[46] Chen, Y.-Y.; Gong, G.-F.; Fan, Y.-Q.; Zhou, Q.; Zhang, Q.-P.; Yao, H.; Zhang, Y.-M.; Wei, T.-B.; Lin, Q. A novel AIE-based supramolecular polymer gel serves as an ultrasensitive detection and efficient separation material for multiple heavy metal ions. Soft Matter 2019, 15, 6878-6884.

[47] Dastidar, P.; Ganguly, S.; Sarkar, K. Metallogels from Coordination Complexes, Organometallic, and Coordination Polymers. Chem. Asian J. 2016, 11, 2484-2498.

[48] Panja, A.; Ghosh, K. Cholesterol-based diazine derivative: selective sensing of $\mathrm{Ag}+$ and $\mathrm{Fe}^{3+}$ ions through gelation and the performance of metallogels in dye and picric acid adsorption from water. Mater. Chem. Front. 2018, 2, 2286-2296.

[49] Adarsh, N. N.; Dastidar, P. Coordination polymers: what has been achieved in going from innocent 4,4'-bipyridine to bis-pyridyl ligands having a non-innocent backbone? Chem./ Soc. Rev. 2012, 41, 3039-3060.

[50] Mishra, A.; Gupta, R. Supramolecular architectures with pyridineamide based ligands: discrete molecular assemblies and their applications. Dalton Trans. 2014, 43, 7668-7682.

[51] Li, B.; He, T.; Fan, Y.; Yuan, X.; Qiu, H.; Yin, S. Recent developments in the construction of metallacycle/metallacagecored supramolecular polymers via hierarchical self-assembly. Chem. Commun. 2019, 55, 8036-8059.

[52] Karak, S.; Kumar, S.; Bera, S.; Díaz, D. D.; Banerjee, S.; Vanka, K.; Banerjee, R. Interplaying anions in a supramolecular metallohydrogel to form metal organic frameworks. Chem. Commun. 2017, 53, 3705-3708.

[53] Dey, S.; Datta, D.; Chakraborty, K.; Nandi, S.; Anoop, A.; Pathak, T. A coordination-assisted general approach to nickel-based nano metallogels. RSC Adv. 2013, 3, 9163-9166.

[54] Po, C.; Yam, V. W.-W. Metallosupramolecular Soft Materials: Metallogels. In Functional Metallosupramolecular Materials, Chapter 6, The Royal Society of Chemistry, UK, 2015, pp. 149-191.

[55] Panja, S.; Adams, D. J. Pathway dependence in redox driven metal-organic gels. Chem. Eur. J. 2020, DOI: 10.1002/chem. 202001051.

[56] Ghosh, K.; Panja, S.; Bhattacharya, S. Visual Sensing of $\mathrm{Ag}^{+}$Ions through Gelation of Cholesterol- Appended Benzimidazole and Associated Ion Conducting Behaviour. ChemistrySelect 2017, 2, 959-966.

[57] Tautz, M.; Torras, J.; Grijalvo, S.; Eritja, R.; Saldías, C.; Alemán, C.; Díaz, D. D. Expanding the limits of amide-triazole isosteric substitution in bisamide-based physical gels. RSC Adv. 2019, 9, 20841-20851.

[58] Ghosh, K.; Panja, A.; Panja, S. Cholesterol appended bis-1,2,3-triazoles as simple supramolecular gelators for the naked eye detection of $\mathrm{Ag}^{+}, \mathrm{Cu}^{2+}$ and $\mathrm{Hg}^{2+}$ ions. New J. Chem. 2016, 40, 3476-3483.

[59] Panja, A.; Ghosh, K. Azo and imine functionalized 2-naphthols: promising supramolecular gelators for selective detection of $\mathrm{Fe}^{3+}$ and $\mathrm{Cu}^{2+}$, reactive oxygen species and halides. Mater. Chem. Front. 2018, 2, 1866-1875.

[60] Raza, R.; Dey, N.; Panja, A.; Ghosh, K. Pyridyl Azo-Based Progelator in Selective Sensing of $\mathrm{Hg}^{2+}$ and $\mathrm{Ag}^{+}$Ions via Sol to Gel Conversion. ChemistrySelect 2019, 4, 11564-11571.

[61] Offiler, C. A.; Jones, C. D.; Steed, J. W. Metal 'turn-off', anion 'turn-on' gelation cascade in pyridinylmethyl ureas. Chem. Commun. 2017, 53, 2024-2027.

[62] Wang, H.; Wang, P.; Huang, C.; Chang, L.; Wu, J.; Hou, H.; Fan, Y. Construction of a series of mercury(II) complexes based on a bis-pyridyl-bis-amide ligand: Effect of counter anions, interactions on the supermolecular structures. Inorg. Chim. Acta 2011, 378, 326-332.

[63] Lin, H.-Y.; Luan, J.; Wang, X.-L.; Liu, G.-C.; Zhang, J.-W. Three Transition Metal(II) Coordination Polymers Constructed by a Semi-rigid Bis-pyridyl-bis-amide and Dicarboxylates Mixed Ligands: Assembly, Structures and Properties. Z. anorg. allg. Chem. 2014, 640, 2041-2048.

[64] Zhang, X.-m.; Ning, Y.; Meng, L.-n.; Li, J.-q.; Luo, M.-b.; Luo, F. Constructing various metal-organic frameworks by mixed pyridine-acylamide and carboxylate ligands: ring-like or helical building blocks. CrystEngComm 2014, 16, 7440-7451.

[65] Wang, X.; Le, M.; Lin, H.; Luan, J.; Liu, G.; Liu, D. Aminopyridine derivatives controlled the assembly and various properties of Cu-BTC metal-organic frameworks. Dalton Trans. 2015, 44, 14008-14018.

[66] Ganguly, S.; Parveen, R.; Dastidar, P. Rheoreversible Metallogels Derived from Coordination Polymers. Chem. Asian J. 2018, 13, 1474-1484.

[67] Geiger, H. C.; Geiger, D. K.; Roberts, W. R.; Morell, D. L.; Huttunen, P.; Schulman, J. L.; Tran, M.; Farthing, D. Non-Steroidal Biphenyl Gelators: Correlation of Xerogel Structure with Solid-State Structure and Circular Dichroism Spectroscopy. Gels 2018, 4, 34.

[68] Portada, T.; Molčanov, K.; Šijaković Vujičić, N.; Žinić, M. Biphenyl Bis(amino alcohol) Oxalamide Gelators: Complex Gelation Involving Coupled Equilibria, Central-to-Axial Chirality Transfer, Dia-stereoisomer Interconversion, and Self-Sorting. Eur. J. Org. Chem. 2016, 2016, 1205-1214.

[69] Tatikonda, R.; Bertula, K.; Nonappa; Hietala, S.; Rissanen, K. Haukka, M. Bipyridine based metallogels: an unprecedented difference in photochemical and chemical reduction in the in situ nanoparticle formation. Dalton Trans. 2017, 46, 2793-2802.

[70] Nakamura, T.; Takashima, Y.; Hashidzume, A.; Yamaguchi, H.; Harada, A., A metal-ion-responsive adhesive material via switching of molecular recognition properties. Nat. Commun. 2014, 5, 4622.

[71] Ruiz-Palomero, C.; Soriano, M. L.; Valcárcel, M. Gels based on nanocellulose with photosensitive ruthenium bipyridine moieties as sensors for silver nanoparticles in real samples. Sens. Actuators, $B$ 2016, 229, 31-37.

[72] Chujo, Y.; Sada, K.; Saegusa, T. Synthesis of Bipyridyl-Branched Polyoxazoline and Its Gelation by Means of Metal Coordination. Polym. J. 1993, 25, 599-608.

[73] Kaes, C.; Katz, A.; Hosseini, M. W. Bipyridine: The Most Widely Used Ligand. A Review of Molecules Comprising at Least Two 2,2'-Bipyridine Units. Chem. Rev. 2000, 100, 3553-3590.

[74] Ghosh, K.; Panja, S.; Bhattacharya, S. Naphthalene linked pyridyl urea as a supramolecular gelator: a new insight into naked eye detection of $\mathrm{I}^{-}$in the gel state with semiconducting behaviour. RSC Adv. 2015, 5, 72772-72779.

[75] Huang, Y.; Zhang, X.; Cui, W.; Wang, X.; Li, B.; Zhang, Y.; Yang, J. Novel liquid crystalline organogelators based on terephthalic acid and terephthalaldehyde derivatives: properties and promotion through the formation of halogen bonding. New J. Chem. 2020, 44, 614-625.

[76] Zhang, Y.-J.; Shen, F.-J.; Li, Y.-J.; Pang, X.-L.; Zhang, C.; Ren, J.-J.; Yu, X.-D. A Zr-cluster based thermostable, self-healing and adaptive metallogel with chromogenic properties responds to multiple stimuli with reversible radical interaction. Chem. Commun 2020, 56, 2439-2442.

[77] Shang, H.; Ding, Z.; Shen, Y.; Yang, B.; Liu, M.; Jiang, S. Multi-color tunable circularly polarized luminescence in one single AIE system. Chem. Sci. 2020, 11, 2169-2174.

[78] Lee, J. H.; Kang, S.; Lee, J. Y.; Jung, J. H. A tetrazole-based metallogel induced with $\mathrm{Ag}^{+}$ion and its silver nanoparticle in catalysis. Soft Matter 2012, 8, 6557-6563.

[79] Ma, Y.; Cametti, M.; Džolić, Z.; Jiang, S. Selective Cu(ii) sensing by a versatile AIE cyanostilbene-based gel system. Soft Matter 2019, 
$15,6145-6150$.

[80] Xing, B.; Choi, M.-F.; Xu, B. A stable metal coordination polymer gel based on a calix[4]arene and its "uptake" of non-ionic organic molecules from the aqueous phase. Chem. Commun. 2002, 362-363.

[81] Zhong, J.-L.; Jia, X.-J.; Liu, H.-J.; Luo, X.-Z.; Hong, S.-G.; Zhang, N.; Huang, J.-B. Self-assembled metallogels formed from $\mathrm{N}, \mathrm{N}^{\prime}, \mathrm{N}^{\prime}$-tris(4-pyridyl)trimesic amide in aqueous solution induced by $\mathrm{Fe}(\mathrm{iii} / \mathrm{Fe}(\mathrm{ii)})$ ions. Soft Matter 2016, 12, 191-199.

[82] Sengupta, S.; Goswami, A.; Mondal, R. Silver-promoted gelation studies of an unorthodox chelating tripodal pyridine-pyrazolebased ligand: templated growth of catalytic silver nanoparticles, gas and dye adsorption. New J. Chem. 2014, 38, 2470-2479.

[83] Rajamalli, P.; Malakar, P.; Atta, S.; Prasad, E. Metal induced gelation from pyridine cored poly(aryl ether) dendrons with in situ synthesis and stabilization of hybrid hydrogel composites. Chem. Commun. 2014, 50, 11023-11025.

[84] Byrne, J. P.; Kitchen, J. A.; Kotova, O.; Leigh, V.; Bell, A. P.; Boland, J. J.; Albrecht, M.; Gunnlaugsson, T. Synthesis, structural, photophysical and electrochemical studies of various d-metal complexes of btp [2,6-bis(1,2,3-triazol-4-yl)pyridine] ligands that give rise to the formation of metallo-supramolecular gels. Dalton Trans. 2014, 43, 196-209.

[85] Tatikonda, R.; Bulatov, E.; Özdemir, Z.; Nonappa; Haukka, M. Infinite coordination polymer networks: metallogelation of aminopyridine conjugates and in situ silver nanoparticle formation. Soft Matter 2019, 15, 442-451.

[86] Wang, X.; He, T.; Yang, L.; Wu, H.; Yin, J.; Shen, R.; Xiang, J.; Zhang, Y.; Wei, C. Designing isometrical gel precursors to identify the gelation pathway for nickel-selective metallohydrogels. Dalton Trans. 2016, 45, 18438-18442.

[87] Byrne, P.; Lloyd, G. O.; Applegarth, L.; Anderson, K. M.; Clarke, N.; Steed, J. W. Metal-induced gelation in dipyridyl ureas. New J. Chem. 2010, 34, 2261-2274.

[88] He, Y.; Bian, Z.; Kang, C.; Cheng, Y.; Gao, L. Chiral binaphthylbisbipyridine-based copper(i) coordination polymer gels as supramolecular catalysts. Chem. Commun. 2010, 46, 3532-3534.

[89] Jie, K.; Zhou, Y.; Shi, B.; Yao, Y. A Cu ${ }^{2+}$ specific metallohydrogel: preparation, multi-responsiveness and pillar[5]arene-induced morphology transformation. Chem. Commun. 2015, 51, 8461-8464.

[90] Singha Mahapatra, T.; Singh, H.; Maity, A.; Dey, A.; Pramanik, S. K.; Suresh, E.; Das, A. White-light-emitting lanthanide and lanthanideiridium doped supramolecular gels: modular luminescence and stimuli-responsive behaviour. J. Mater. Chem. C 2018, 6, 97569766.

[91] Panja, A.; Ghosh, K. Pyridylazo Derivatives with Dicyanovinyl Appendage in Selective Sensing of $\mathrm{CN}^{-}$in Sol-Gel Medium. ChemistrySelect 2018, 3, 1809-1814.

[92] Panja, A.; Ghosh, K. Pyridyl Azo-Based Naphthyl Acetate for
Sensing of Hydrazine and Perborate in Sol-Gel Medium. ChemistrySelect 2018, 3, 9448-9453.

[93] Ghosh, K.; Panja, S. Naphthalene-cholesterol conjugate as simple gelator for selective sensing of $\mathrm{CN}^{-}$ion. Supramol. Chem. 2017, 29, 350-359.

[94] Carter, K. P.; Young, A. M.; Palmer, A. E. Fluorescent Sensors for Measuring Metal lons in Living Systems. Chem. Rev. 2014, 114, 4564-4601.

[95] Ye, J.-H.; Duan, L.; Yan, C.; Zhang, W.; He, W. A new ratiometric $\mathrm{Ag}^{+}$fluorescent sensor based on aggregation-induced emission. Tetrahedron Lett. 2012, 53, 593-596.

[96] Qian, X.; Xu, Z. Fluorescence imaging of metal ions implicated in diseases. Chem. Soc. Rev. 2015, 44, 4487-4493.

[97] Anichini, C.; Czepa, W.; Pakulski, D.; Aliprandi, A.; Ciesielski, A.; Samorì, P. Chemical sensing with 2D materials. Chem. Soc. Rev. 2018, 47, 4860-4908.

[98] Zhang, Q.; Wang, C.-F.; Lv, Y.-K. Luminescent switch sensors for the detection of biomolecules based on metal-organic frameworks. Analyst 2018, 143, 4221-4229.

[99] Li, J.; Yim, D.; Jang, W.-D.; Yoon, J. Recent progress in the design and applications of fluorescence probes containing crown ethers. Chem. Soc. Rev. 2017, 46, 2437-2458.

[100] Fan, L.-J.; Zhang, Y.; Murphy, C. B.; Angell, S. E.; Parker, M. F. L.; Flynn, B. R.; Jones, W. E. Fluorescent conjugated polymer molecular wire chemosensors for transition metal ion recognition and signaling. Coord. Chem. Rev. 2009, 253, 410-422.

[101] Li, Z.; Askim, J. R.; Suslick, K. S. The Optoelectronic Nose: Colorimetric and Fluorometric Sensor Arrays. Chem. Rev. 2019, 119, 231-292.

[102] Kwon, N.; Hu, Y.; Yoon, J. Fluorescent Chemosensors for Various Analytes Including Reactive Oxygen Species, Biothiol, Metal lons, and Toxic Gases. ACS Omega 2018, 3, 13731-13751.

[103] Panja, S.; Debnath, S.; Ghosh, K. Fluorophore inserted bisbenzimidazole clefts in selective sensing of $\mathrm{Ag}^{+}$and $\mathrm{Cu}^{2+}$ ions. $\mathrm{J}$. Photochem. Photobiol. A: Chem. 2017, 348, 110-117.

[104] Ghosh, K.; Panja, S.; Sarkar, T. Rhodamine-linked pyridyl thiourea as a receptor for selective recognition of $\mathrm{F}^{-}, \mathrm{Al}^{3+}$ and $\mathrm{Ag}^{+}$under different conditions. Supramol. Chem. 2015, 27, 490-500.

[105] Ghosh, K.; Panja, S., Cholesterol-based Bisamides on Biphenyl Backbone: A Case of Selective Visual Sensing of $\mathrm{F}^{-}$and $\mathrm{H}_{2} \mathrm{PO}^{4-}$ through Breaking and Making of Gels. ChemistrySelect 2016, 1, 3667-3674.

[106] Chou, P.-T.; Wu, G.-R.; Wei, C.-Y.; Cheng, C.-C.; Chang, C.-P.; Hung, F.-T. Excited-State Amine-Imine Double Proton Transfer in 7-Azaindoline. J. Phys. Chem. B 2000, 104, 7818-7829.

Received April 2, 2020 Accepted May 8, 2020 